\title{
Cross-cultural adaptation of the Perceived Risk of HIV Scale in Brazilian Portuguese
}

\author{
Thiago S. Torres ${ }^{1 *} \mathbb{D}$, Paula M. Luz ${ }^{1}$, Luana M. S. Marins ${ }^{1}$, Daniel R. B. Bezerra ${ }^{1}$, Celline C. Almeida-Brasil², \\ Valdilea G. Veloso' ${ }^{1}$ Beatriz Grinsztejn' ${ }^{1}$, Daphna Harel ${ }^{3,4}$ and Brett D. Thombs ${ }^{5,6}$
}

\begin{abstract}
Background: Valid and reliable instruments are needed to measure the multiple dimensions of perceived risk. The Perceived Risk of HIV Scale is an 8-item measure that assesses how people think and feel about their risk of infection. We set out to perform a cross-cultural adaptation of the scale to Brazilian Portuguese among key populations (gay, bisexual and other men who have sex with men and transgender/non-binary) and other populations (cisgender heterosexual men and cisgender women).

Methods: Methodological study with cross-sectional design conducted online during October/2019 (key populations [sample 1] and other populations) and February-March/2020 (key populations not on pre-exposure prophylaxis [sample 2]). Cross-cultural adaptation of the Perceived Risk of HIV Scale followed Beaton et al. 2000 guidelines and included confirmatory factor analysis, differential item functioning (DIF) using the Multiple-Indicator Multiple-Cause model, and concurrent validity to verify if younger individuals, those ever testing for HIV, and engaging in high-risk behaviors had higher scores on the scale.
\end{abstract}

Results: 4342 participants from key populations (sample $1=235$; sample $2=4107$ ) and 155 participants from other populations completed the measure. We confirmed the single-factor structure of the original measure (fit indices for sample 1 plus other populations: $C F I=0.98, T L I=0.98, \mathrm{RMSEA}=0.07$; sample 2 plus other populations: $\mathrm{CFI}=0.97$, $T L I=0.95$, RMSEA $=0.09$ ). For the comparisons between key populations and other populations, three items (item 2 : "I worry about getting infected with HIV", item 4:"I am sure I will not get infected with HIV", and item 8: "Getting HIV is something I have") exhibited statistically significant DIF. Items 2 and 8 were endorsed at higher levels by key populations and item 4 by other populations. However, the effect of DIF on overall scores was negligible $(0.10$ and 0.02 standard deviations for the models with other populations plus sample 1 and 2, respectively). Those ever testing for HIV scored higher than those who never tested $(p<.001)$; among key populations, those engaging in high-risk behaviors scored higher than those reporting low-risk.

Conclusion: The Perceived Risk of HIV Scale can be used among key populations and other populations from Brazil.

Keywords: Perceived risk of HIV Scale, Psychometric properties, GBM, Transgender, HIV perceived risk, HIV riskbehavior, Brazil

*Correspondence: thiago.torres@ini.fiocruz.br

${ }^{1}$ Instituto Nacional de Infectologia Evandro Chagas, Fundação Oswaldo Cruz, Av. Brasil 4365, Manguinhos, Rio de Janeiro 21040-900, Brazil

Full list of author information is available at the end of the article

\section{Background}

By 2018, more than 900,000 individuals were living with HIV in Brazil [1]. National Surveillance data indicates that more than 300,000 new HIV infections were diagnosed from 2007 to $2019,69 \%$ of them among males [2]. Like other Latin American countries, the HIV epidemic in Brazil disproportionally affects key populations, with original author(s) and the source, provide a link to the Creative Commons licence, and indicate if changes were made. The images or other third party material in this article are included in the article's Creative Commons licence, unless indicated otherwise in a credit line to the material. If material is not included in the article's Creative Commons licence and your intended use is not permitted by statutory regulation or exceeds the permitted use, you will need to obtain permission directly from the copyright holder. To view a copy of this licence, visit http://creativecommons.org/licenses/by/4.0/. The Creative Commons Public Domain Dedication waiver (http://creativeco mmons.org/publicdomain/zero/1.0/) applies to the data made available in this article, unless otherwise stated in a credit line to the data. 
gay, bisexual and other cisgender men who have sex with men (GBM) and transgender women who have sex with men (TGW) facing the highest burden [3]. HIV prevalence is estimated at 18\% among GBM [4] and 31\% among TGW [5], while it is below $0.5 \%$ among the general population [2].

Prior studies have shown that Brazilian GBM and TGW engage to a higher degree in behaviors associated with increased HIV risk, such as condomless receptive anal sex [5-9] and use of alcohol or illicit drugs before or during sex ('chemsex') [10]. Although currently the effect of these behaviors may be mitigated by pre-exposure prophylaxis (PrEP) and treatment as prevention, which are available free of charge through the Brazilian Public Health System [11], results from web-based surveys have shown that almost $30 \%$ of Brazilian GBM have never heard of PrEP [7] and 17\% were never tested for HIV, with higher proportions in lower income regions [12]. In this sense, it is important to identify predictors of engagement in high-risk behavior among key populations in Brazil.

According to the Health Belief Model, individuals who perceive themselves at higher risk of a particular health problem are more likely to engage in behaviors to help reduce their risk [13]. Other theoretical models also consider perceived risk as an important correlate of risk behavior, including the AIDS Risk Reduction Model [14]. Prior studies that have accessed perceived HIV risk among Brazilian GBM and TGW have done so using a single question focusing mainly on the likelihood or the cognitive assessment of risk: "In your opinion, what is your risk of getting HIV in the next year?" with possible response options "No risk", "Low risk", "High risk", "Certain" and "I don't know/prefer not to answer" [6, 7, 9, 15-17]. However, HIV risk perception is complex, and requires a valid and reliable instrument to measure its multiple dimensions.

The Perceived Risk of HIV Scale [18] is a low burden, self-report 8-item measure developed to assess how people think and feel about their risk of HIV infection based on their previous sexual behavior and covering several dimensions of perceived HIV risk. The scale was initially evaluated using item response theory in a sample of participants recruited from HIV testing and prevention services in Long Beach, California. It assesses three different aspects of perceived HIV risk: cognitive (3-items, e.g., "I think my chances of getting infected with HIV are:", response options: zero, almost zero, small, moderate, large, very large), intuitive (3-items, e.g., "I feel vulnerable to HIV infection", response options: strongly disagree to strongly agree), and salience (2-items, e.g., "Getting HIV is something I have:", response options: never thought about, rarely thought about, thought about some of the time, thought about often). Response format varies from four to six options depending on the item. The total summed score ranges from 10 to 40 , calculated by adding the score of each item. Higher scores indicate a higher risk perception. Prior research shows that scores on this measure are correlated with past engagement in high-risk behavior, including number of sex partners, condomless anal sex, and sex under influence of substances [18].

The Perceived Risk of HIV Scale was previously validated in European Portuguese in a sample of the general population and among HIV-uninfected partners of serodifferent couples (mostly heterosexuals). The correlation of the scale's scores with engagement in high-risk sexual behavior and with HIV testing provided evidence for criterion validity [19]. However, the application of the European Portuguese version of the scale in Brazil may not be appropriate due to significant cultural and language differences between Brazilian and European Portuguese. Moreover, given the disproportionate impact of the Brazilian HIV epidemic among key populations, a specific evaluation of the scale's validity among these populations is warranted.

This study performed a cross-cultural adaptation of the Perceived Risk of HIV Scale in Brazilian Portuguese among key populations (GBM and transgender/nonbinary) and other populations (cisgender heterosexual men and cisgender women) using established guidelines [20]. We then evaluated its reliability (internal consistency) and validity. Furthermore, we tested for differential item functioning (DIF) to assess measurement invariance among the populations included in our study.

\section{Methods}

\section{Study design}

This is a methodological study with cross-sectional design conducted online during October/2019 (key populations [sample 1] and other populations) and February-March/2020 (key populations not on pre-exposure prophylaxis [sample 2]). Cross-cultural adaptation of the Perceived Risk of HIV Scale followed guidelines proposed by Beaton et al. [20]. This study was not registered in any database.

\section{Step 1: Translation}

We have obtained the necessary permissions from the authors of the Perceived Risk of HIV Scale to modify it. Translation of the items of the scale into Brazilian Portuguese was performed by three independent translators (two researchers and a linguistics professor fluent in both languages), after which a meeting was held to discuss and reach a consensus translated version of the scale. Then, three additional independent reviewers (two language teachers and one professional translator) translated the 
Portuguese version back to English, after which another meeting was held with the six members of the translation team and a mediator who was a member of the research team to compare the original items with the back-translated items and identify where items or words seemed to differ. In this final meeting the team reached an agreedon version based on the comments, the original items, and the translated items. Next, two experts evaluated the translated items vis-à-vis the original subscales to judge if, in their opinion, they captured the concepts as defined. Finally, a qualitative pretesting of the resulting items was conducted with a small convenience sample to ensure item comprehensibility before moving into the second step of this study. For this, we invited via WhatsApp groups, GBM aged 18 years or older who had previously sought HIV testing and prevention services at Instituto Nacional de Infectologia Evandro Chagas (INI-Fiocruz), Rio de Janeiro, Brazil. An electronic version of the scale was provided and participants were requested to judge the clarity of each item on a scale from 0 to 10 , and, if an item was scored as 7 or lower, an additional open text field was provided and the participant was asked to state what was unclear and to provide suggestions to improve clarity. A group meeting of the research team was held to discuss the suggestions made and items were adjusted as needed to improve understanding.

\section{Step 2: Reliability and construct validity}

A first convenience sample of adult Brazilians was recruited through advertisements on different platforms:

(1) Facebook and WhatsApp, two social media apps; and

(2) Grindr, a geospatial network app for sexual encounters for GBM and transgender/non-binary people. Participant eligibility included age $\geq 18$ years and residency in Brazil. To decrease participant burden, random allocation of eligible participants to different instruments was performed such that each participant only responded to one instrument. Exclusion criteria for this analysis were self-report of HIV positive status, no response in questions about HIV testing or HIV status, an incorrect response to any of three attention questions which were included throughout the survey instrument at approximately every 15 items [21], and having responded to the survey previously (see Fig. 1: Participant flow chart). In order to provide more evidence of the scale's construct validity, we recruited a second convenience sample including only key populations. This time, the survey was launched through advertisements on Hornet, another geospatial network app for GBM and transgender/nonbinary people. The same inclusion and exclusion criteria detailed above were used. Additionally, we excluded from this analysis those who ever used PrEP given that PrEP use reduces the risk of HIV transmission irrespective of one's sexual behavior [22, 23].

The surveys were programmed on Alchemer ${ }^{\circledR}$. The researchers checked the usability and technical functionality of the electronic questionnaire in multiple platforms (devices and operating systems) before starting the survey. The survey was open (not password-protected) and not mandatory for app users. Mobile version of the survey had one question per page, and number of pages depended on the chosen answers (adaptative questioning). All survey items had a non-response option ("I don't want to answer").

The survey instrument was divided into three sections as follows. Section 1 included items on socio-demographic information (age, race/ethnicity, gender, sexual orientation, education, income, and state of residence), and Sect. 2 included items referring to prior HIV testing and HIV test result. If HIV negative or unknown status, participants answered Sect. 3 which included the items of the translated scale (Additional file 1). As in the original scale [18], response options for the translated scale were on 4, 5 or 6-point Likert type and the total score was calculated by adding the score of each item (with item 4 being reverse coded and some response options for items 1, 2, 5 and 6 recoded). Higher scores indicated greater risk perception. A fourth section was included in the survey launched in Hornet in 2020 with questions about sexual behavior during the previous 6 months (number of male sexual partners, condomless receptive anal sex, sex with HIV positive partner, number of insertive anal intercourses with HIV positive partner), and use of stimulants. These questions (in addition to age) constitute the HIV Incidence Risk Index for men who have sex with men (HIRI-MSM), a 7-item risk score developed by Smith et al. [24] to predict HIV seroconversion among GBM that is recommended by the Centers for Disease Control and Prevention to screen individuals who should be evaluated for PrEP use [25]. Scores $<10$ and $\geq 10$ were considered as "low risk" and "high risk", respectively [24, 25].

Based on responses to items on gender identity and sexual orientation, participants were allocated in three groups: (1) key populations (sample 1): GBM, transgender and non-binary individuals recruited during October 2019 via Grindr; (2) key populations (sample 2): GBM, transgender and non-binary individuals recruited during February and March 2020 via Hornet; (3) other populations: heterosexual cisgender men and cisgender women.

\section{Statistical analysis}

Socio-demographic characteristics of key populations (samples 1 and 2) and other populations were described. Procedures to assess differential item functioning 


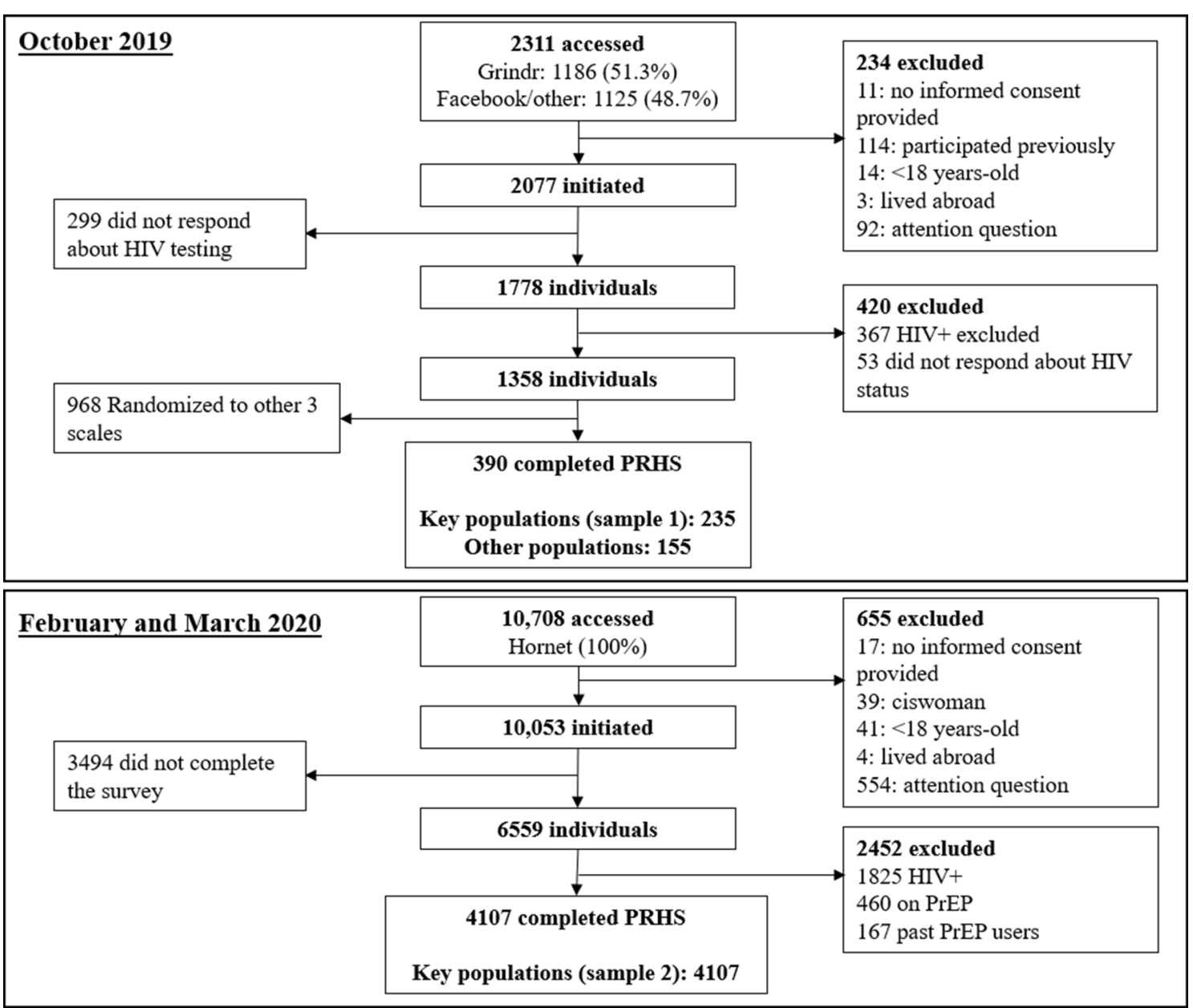

Fig. 1 Participant flow chart

followed a previously described protocol [26]. We first tested the original factor structure of the Perceived Risk of HIV Scale for the three groups separately using confirmatory factor analysis (CFA), using the weighted least squares estimator with a diagonal weight matrix, robust standard errors, and a mean- and variance-adjusted chi-square statistic with delta parameterization [27]. To assess model fit, the chi-square test, Tucker-Lewis Index (TLI) [28], Comparative Fit Index (CFI) [29] and Root Mean Square Error of Approximation (RMSEA) [30] were used. Since the chi-square test is highly sensitive to sample size, it can lead to the rejection of well-fitting models [31]. Therefore, the TLI, CFI and RMSEA fit indices were emphasized. Good fitting models were indicated by a TLI and CFI $\geq 0.95$ and RMSEA $\leq 0.06$ [32]. Once the factor structure was established for each group separately, two CFA models were fit combining participants from (1) key populations from sample 1 and other populations and (2) key populations from sample 2 and other populations. Modification indices were used to identify pairs of items for which model fit would improve if error estimates were freed to covary and for which there was theoretical justification [27]. We used theta parameterization after inclusion of error terms for correlated items [33].

To determine whether the Perceived Risk of HIV Scale items exhibited DIF for participants from key populations versus other populations, multiple indicator multiple cause (MIMIC) models were used. MIMIC models assess the relationship between the factors and a set of covariates to understand measurement invariance and population heterogeneity. The base MIMIC model consists of the CFA factor model with an added direct effect of group on the latent factors. This serves to control for group differences on the latent factor. We followed standard procedures for MIMIC analyses [26] which consist of regressing each item separately on the grouping variable to assess potential DIF. The presence of substantive DIF could threaten the validity of group comparisons. DIF was confirmed by a statistically significant $(p<0.05)$ link 
of group with the item, controlling for differences in the overall level of the latent factor. Once all items with significant DIF were identified, the magnitude of DIF items collectively was evaluated by comparing the difference on the latent factor between groups in the baseline model and after controlling for DIF.

We estimated the scale's internal consistency using Cronbach's alpha (assumed acceptable if $>0.7$ ) [34]. To assess concurrent validity, we used t-tests to evaluate if participant's scores on the Perceived Risk of HIV Scale differed by age (18-24 vs. $\geq 25$ years) and by prior HIV testing (yes vs. no) for key populations and other populations separately. We hypothesized that younger individuals (18-24 years vs. $\geq 25$ years) and those who had previously tested for HIV (vs. not) would score higher on the Perceived Risk of HIV scale. Lastly, we used t-tests to evaluate if Perceived Risk of HIV scores were higher among key populations from sample 2 who reported engaging in high-risk sexual behaviors measured by condomless receptive anal sex (yes vs. no), number of male partners ( $\leq 5$ vs. $>5$ ) and the HIRI-MSM risk scale (low risk vs. high risk).

CFA and MIMIC analyses were carried out in Mplus version 8.4 [27]; all other analyses were performed in $R$ version 4.0.1 [35].

\section{Results}

\section{Step 1: Translation}

The qualitative pretesting of the final translated version was performed with $80 \mathrm{GBM}$, most were aged $\geq 25$ years
(79\%), had finished college or higher education (74\%), and lived in the city of Rio de Janeiro (69\%). Most participants (ranging from 89 to $100 \%$ ) judged each item's clarity with a score of 7 or higher; average clarity scores varied from 9.4 for item 1 to 9.8 for item 2, 7 and 8. Item 1 was slightly modified as a function of the suggestions made by participants. The post-pretesting version of the translated scale is given in Table 1.

\section{Step 2: Validation \\ Sample characteristics}

In October 2019, a total of 2311 individuals accessed the questionnaire and 1358 (59\%) completed all items. Of these, 390 were randomized to complete the translated version of the Perceived Risk of HIV Scale (Fig. 1), including 235 from key populations (sample 1) and 155 from other populations. During February and March 2020 , a total of 10,708 participants accessed the questionnaire, and 6559 completed it. Of these, 4107 self-reported HIV negative or unknown status and were not currently using PrEP. Socio-demographic characteristics for key populations (sample 1 and sample 2) and other populations are displayed in Table 2.

Key populations (Sample 1) In total, 235 GBM and trans/non-binary participants completed the translated version of the Perceived Risk of HIV Scale. Median age was 33 years (IQR: 27-41), the majority were cisgender men (97\%), 186 (79\%) were gay, 135 (57\%) were White, 80 (34\%) reported low-income, 159 (68\%) reported college

Table 1 The 8 final items of the translated Perceived Risk of HIV Scale with item-specific response options given in parenthesis

\begin{tabular}{|c|c|c|c|}
\hline \#\# & Original item & Range & Final Brazilian Portuguese translation \\
\hline i01 & $\begin{array}{l}\text { What is your gut feeling about how likely you are to get infected } \\
\text { with HIV? (Extremely unlikely to Extremely likely) }\end{array}$ & $1-4$ & $\begin{array}{l}\text { Na sua opinião, qual sua chance de pegar HIV? (Extremante } \\
\text { improvável a Extremamente provável) }\end{array}$ \\
\hline i02 & $\begin{array}{l}\text { I worry about getting infected with HIV. (None of the time to All of } \\
\text { the time) }\end{array}$ & $1-4$ & Eu me preocupo se vou pegar HIV (Nunca a sempre) \\
\hline i03 & $\begin{array}{l}\text { Picturing self getting HIV is something I find: (Very hard to do to } \\
\text { Very easy to do) }\end{array}$ & $1-4$ & $\begin{array}{l}\text { Me imaginar pegando HIV é algo que acho: (Muito difícil a Muito } \\
\text { fácil) }\end{array}$ \\
\hline i04 & $\begin{array}{l}\text { I am sure I will NOT get infected with HIV. (Strongly disagree to } \\
\text { Strongly agree) }\end{array}$ & $1-6$ & $\begin{array}{l}\text { Tenho certeza de que NÃO vou pegar HIV (Discordo fortemente a } \\
\text { Concordo fortemente) }\end{array}$ \\
\hline i05 & $\begin{array}{l}\text { I feel vulnerable to HIV infection. (Strongly disagree to Strongly } \\
\text { agree) }^{\mathrm{a}}\end{array}$ & $1-6$ & $\begin{array}{l}\text { Me sinto vulnerável à infecção pelo HIV (Discordo fortemente a } \\
\text { Concordo fortemente) }\end{array}$ \\
\hline i06 & $\begin{array}{l}\text { There is a chance, no matter how small, I could get HIV. (Strongly } \\
\text { disagree to Strongly agree) }\end{array}$ & $3-6$ & $\begin{array}{l}\text { Existe uma chance, ainda que mínima, que eu pegue HIV (Discordo } \\
\text { fortemente a Concordo fortemente) }\end{array}$ \\
\hline i07 & $\begin{array}{l}\text { I think my chances of getting infected with HIV are: (Zero to Very } \\
\text { large) }\end{array}$ & $1-6$ & Acho que meu risco de pegar HIV é: (Zero a Muito alta) \\
\hline i08 & $\begin{array}{l}\text { Getting HIV is something I have: (Never thought about to Thought } \\
\text { about often) }\end{array}$ & $1-4$ & $\begin{array}{l}\text { Pegar HIV é algo em que: (Eu nunca pensei a Pensei frequente- } \\
\text { mente) }\end{array}$ \\
\hline
\end{tabular}

\footnotetext{
affective item

b Salience item

c Cognitive item

d Reversed coded
} 
Table 2 Characteristics of study populations. Brazil, 2019-2020

\begin{tabular}{|c|c|c|c|}
\hline & \multicolumn{2}{|c|}{ Key populations } & \multirow[t]{2}{*}{ Other populations } \\
\hline & Sample 1 & Sample 2 & \\
\hline Total & 235 & 4107 & 155 \\
\hline \multicolumn{4}{|l|}{ Age } \\
\hline Mean (SD) & $34.6(10.1)$ & $34.2(10.4)$ & $46.9(16.1)$ \\
\hline $18-24$ years & $37(15.7)$ & $681(16.6)$ & $16(10.3)$ \\
\hline$\geq 25$ years & $198(84.3)$ & $3426(83.4)$ & $139(89.7)$ \\
\hline \multicolumn{4}{|l|}{ Gender } \\
\hline Cisgender men & 209 (97.4) & 4024 (98.0) & $29(18.7)$ \\
\hline Cisgender women & $0(0)$ & $0(0)$ & $126(81.3)$ \\
\hline Trans/non-binary & $6(2.6)$ & $83(2.0)$ & $0(0)$ \\
\hline \multicolumn{4}{|l|}{ Sexual orientation } \\
\hline Gay & $186(79.1)$ & 3365 (81.9) & $0(0)$ \\
\hline Lesbian & $0(0)$ & $0(0)$ & $7(4.5)$ \\
\hline Bisexual & $45(19.1)$ & $720(17.5)$ & $16(10.3)$ \\
\hline Heterosexual & $4(1.7)$ & $22(0.5)$ & $132(85.2)$ \\
\hline \multicolumn{4}{|l|}{ Race } \\
\hline White & $135(57.4)$ & $2526(63.1)$ & $102(68.0)$ \\
\hline Black & $27(11.5)$ & $394(9.8)$ & $12(8.0)$ \\
\hline Pardo (mixed)/native & $73(31.1)$ & $1085(27.1)$ & $36(24.0)$ \\
\hline \multicolumn{4}{|l|}{ Income $e^{a}$} \\
\hline Low & $80(34.0)$ & $1184(28.8)$ & $43(27.7)$ \\
\hline Middle & 78 (33.2) & $1853(45.1)$ & $75(48.4)$ \\
\hline High & 77 (32.8) & $1070(26.1)$ & $37(23.9)$ \\
\hline \multicolumn{4}{|l|}{ Education $\left(\right.$ years) ${ }^{b}$} \\
\hline$\leq 12$ & $75(32.1)$ & $1278(31.7)$ & $59(38.1)$ \\
\hline$>12$ (college or higher) & $159(67.9)$ & $2754(68.4)$ & $96(61.9)$ \\
\hline \multicolumn{4}{|l|}{ Region } \\
\hline North, Northeast and Central-west & $74(31.5)$ & $319(7.8)$ & $27(17.4)$ \\
\hline Southeast/South & $161(68.5)$ & $3788(92.2)$ & $128(82.6)$ \\
\hline \multicolumn{4}{|l|}{ Current partner } \\
\hline No & $171(72.8)$ & $2818(71.3)$ & $52(33.5)$ \\
\hline Yes & $64(27.2)$ & $1135(28.7)$ & $103(66.5)$ \\
\hline \multicolumn{4}{|l|}{ Last HIV test } \\
\hline Past 3 months & $83(35.3)$ & $1120(27.3)$ & $10(6.5)$ \\
\hline Past 6 months & $34(14.5)$ & $794(19.3)$ & $14(9.0)$ \\
\hline Past 12 months & $32(13.6)$ & $739(18.0)$ & $23(14.8)$ \\
\hline More than 12 months & $56(23.8)$ & $948(23.1)$ & $64(41.3)$ \\
\hline Never & $30(12.8)$ & $506(12.3)$ & $44(28.4)$ \\
\hline \multicolumn{4}{|l|}{ Score } \\
\hline Mean (SD) & $25.8(5.2)$ & $25.7(4.9)$ & $20.5(5.5)$ \\
\hline
\end{tabular}

a We considered the number of minimum wages in the family monthly income: low $\leq 2$, middle $>2-6$, high $>6$ (monthly minimum wage in 2019 was 998 BRL $=$ US\$ 248 , currency from January 2020)

b $\leq 12$ years is equivalent to complete Secondary Education or less, $>12$ is equivalent to complete College education or higher

education or higher. The Perceived Risk of HIV Scale mean score was 25.8 (SD 5.2).

Key populations (Sample 2) In total, 4107 GBM and trans/non-binary participants completed the translated version of the Perceived Risk of HIV Scale. Median age was 32 years (IQR: 26-40), the majority were cisgender men (98\%), 3365 (82\%) were gay, 2526 (63\%) were White, 1184 (29\%) reported low-income, 2754 (68\%) reported college education or higher. According to the HIRI-MSM scale, more than a half of participants could be classified 
as engaging in high-risk behavior (2276, 55\%); 1527 (37\%) reported condomless receptive anal sex and 1650 (40\%) reported more than five male sexual partners in the past 6 months. The Perceived Risk of HIV Scale mean score was 25.7 (SD 4.9).

Other populations In total, 155 participants completed the translated version of The Perceived Risk of HIV Scale. Median age was 48 years (interquartile range [IQR]: $35-59)$, the majority were cisgender women $(81 \%), 132$ (85\%) were heterosexual, 102 (68\%) were White, 43 (28\%) reported low-income, 96 (62\%) reported college education or higher. The Perceived Risk of HIV Scale mean score was 20.5 (SD 5.5).

Comparing the groups (Table 2), we note that participants from key populations were younger, almost all cisgender men (versus cisgender women), gay or bisexual (versus heterosexual), reported higher education though were more likely to be low income, were less likely to have current partner, more likely to have ever tested for HIV, and scored higher in the Perceived Risk of HIV scale than other populations.

\section{Confirmatory factor analysis and differential item functioning}

Factor loadings of the one-factor structure CFA models for key populations sample 1 and 2 and other populations are provided in Table 3. Model's fit for the groups were (1) key populations (sample 1): chi-square $(20)=94.7$, $p \leq 0.001$, CFI $=0.95$, TLI $=0.92$, RMSEA $=0.13 \quad(90 \%$ CI 0.10-0.15); (2) key populations (sample 1): chisquare $(20)=1137.1, p \leq 0.001, \mathrm{CFI}=0.94, \mathrm{TLI}=0.92$,
RMSEA $=0.12$ (90\% CI 0.11-0.12); (3) other populations: chi-square $(20)=93.8, p \leq 0.001, \mathrm{CFI}=0.92, \mathrm{TLI}=0.89$, RMSEA $=0.15$ (90\% CI $0.12-0.19)$. Of note is that the loadings for item 2 were within the expected range for other populations (0.59) but small for key populations (sample 1: 0.20 and sample 2:0.03).

The first single-factor model was fit combining sample 1 key populations and other populations, including a direct effect of group on the latent factor. Results indicate a marginally acceptable fit [chi-square $(27)=241.7$, $p \leq 0.001, \mathrm{CFI}=0.91, \mathrm{TLI}=0.89, \quad \mathrm{RMSEA}=0.14 \quad(90 \%$ CI 0.13-0.16)]. Inspection of modification indices suggested that error terms belonging to items 2 and 8 might be correlated. The re-specified model including the correlation of these items had a moderate acceptable fit [chisquare $(26)=194.6, p \leq 0.001, \mathrm{CFI}=0.93, \mathrm{TLI}=0.91$, RMSEA $=0.13$ (90\% CI 0.11-0.15)].

Prior to accounting for possible DIF, key populations participants (sample 1) had 1.29 SD higher latent factor levels than other populations (see Table $4, p \leq 0.001$ ). DIF analyses indicated that items 2,4 and 8 had statistically significant DIF ( $p \leq 0.001)$, with items 2 and 8 being endorsed at higher levels by key populations and item 4 by other populations. As shown in Table 4, after correcting for DIF, key populations had 1.19 SD higher latent factor levels compared to other populations (i.e., the effect of DIF on overall scores was of 0.10 standard deviations). The final model accounting for DIF had a good fit [chi-square $(23)=62.5, p \leq 0.001, \mathrm{CFI}=0.98, \mathrm{TLI}=0.98$, RMSEA $=0.07$ (90\% CI 0.05-0.09)].

Table 3 Factor loadings of the one-factor CFA models for the Perceived Risk of HIV Scale for key populations sample 1 and 2 and other populations

\begin{tabular}{|c|c|c|c|}
\hline \multirow[t]{2}{*}{ Items } & \multicolumn{2}{|l|}{ Key populations } & \multirow[t]{2}{*}{ Other populations } \\
\hline & Sample 1 & Sample 2 & \\
\hline $\begin{array}{l}\text { i01. What is your gut feeling about how likely you are to get infected } \\
\text { with HIV? }\end{array}$ & 0.741 & 0.766 & 0.795 \\
\hline i02. I worry about getting infected with HIV & 0.201 & 0.033 & 0.590 \\
\hline i03. Picturing self getting HIV is something I find & 0.752 & 0.646 & 0.560 \\
\hline i04. I am sure I will NOT get infected with HIV & 0.636 & 0.635 & 0.593 \\
\hline i05. I feel vulnerable to HIV infection & 0.628 & 0.632 & 0.637 \\
\hline i06. There is a chance, no matter how small, I could get HIV & 0.400 & 0.538 & 0.555 \\
\hline i07. I think my chances of getting infected with HIV are: & 0.918 & 0.868 & 0.853 \\
\hline i08. Getting HIV is something I have: & 0.375 & 0.378 & 0.664 \\
\hline \multicolumn{4}{|l|}{ Fit indices } \\
\hline Chi-square test of model fit & 94.7 & 1137.1 & 93.8 \\
\hline $\mathrm{CFI}$ & 0.95 & 0.94 & 0.92 \\
\hline TLI & 0.92 & 0.92 & 0.89 \\
\hline RMSEA ( $90 \%$ confidence interval) & $0.13(0.10-0.15)$ & $0.12(0.11-0.12)$ & $0.15(0.12-0.19)$ \\
\hline
\end{tabular}


Table 4 Factor loadings for the Perceived Risk of HIV Scale in key populations (sample 1) and other populations and influence of group on the overall estimates of latent factor score

\begin{tabular}{|c|c|c|c|c|}
\hline \multirow[t]{2}{*}{ Items } & \multicolumn{2}{|l|}{ Base model $^{a}$} & \multicolumn{2}{|c|}{ DIF corrected model ${ }^{b}$} \\
\hline & Factor loading & $95 \% \mathrm{Cl}$ & Factor loading & $95 \% \mathrm{Cl}$ \\
\hline $\begin{array}{l}\text { 101. What is your gut feeling about how likely you are to get } \\
\text { infected with HIV? }\end{array}$ & 0.808 & $0.76,0.85$ & 0.806 & $0.77,0.84$ \\
\hline i02. I worry about getting infected with HIV & 0.406 & $0.30,0.51$ & 0.284 & $0.20,0.37$ \\
\hline i03. Picturing self getting HIV is something I find & 0.710 & $0.65,0.77$ & 0.706 & $0.66,0.76$ \\
\hline i04. I am sure I will NOT get infected with HIV & 0.642 & $0.58,0.70$ & 0.685 & $0.62,0.75$ \\
\hline i05. I feel vulnerable to HIV infection & 0.678 & $0.62,0.74$ & 0.673 & $0.62,0.72$ \\
\hline i06. There is a chance, no matter how small, I could get HIV & 0.512 & $0.43,0.59$ & 0.508 & $0.44,0.58$ \\
\hline i07. I think my chances of getting infected with HIV are & 0.914 & $0.88,0.94$ & 0.913 & $0.89,0.94$ \\
\hline i08. Getting HIV is something I have & 0.511 & $0.42,0.60$ & 0.431 & $0.35,0.51$ \\
\hline \multicolumn{5}{|l|}{ Structural effect } \\
\hline Group on latent factor ${ }^{c}$ & 1.287 & $0.96,1.61$ & 1.192 & $0.87,1.51$ \\
\hline \multicolumn{5}{|l|}{ Direct effect on item attributable to group ${ }^{c}$} \\
\hline i02 & & & 1.041 & $0.78,1.30$ \\
\hline i04 & & & -0.504 & $-0.76,-0.25$ \\
\hline i08 & & & 0.616 & $0.37,0.86$ \\
\hline
\end{tabular}

Bold indicate $p$ value $\leq 0.001$

DIF differential item functioning

${ }^{\text {a }}$ Not corrected for DIF

${ }^{\text {b }}$ Correct for DIF for items 2, 4 and 8

c Other populations used as reference

The second single-factor model was fit combining the sample 2 key populations and other populations, including a direct effect of group on the latent factor. Results indicate a marginally acceptable fit [chisquare $(27)=1722.7, p \leq 0.001, \mathrm{CFI}=0.92, \mathrm{TLI}=0.89$, RMSEA $=0.12(90 \%$ CI $0.12-0.13)]$. Similar to results above, inspection of modification indices suggested that error terms belonging to items 2 and 8 should be correlated. The re-specified model including the effect of these items had a marginally acceptable fit [chisquare $(26)=1323.8, p \leq 0.001, \mathrm{CFI}=0.94, \mathrm{TLI}=0.92$, RMSEA $=0.11$ (90\% CI 0.10-0.11)].

Prior to accounting for possible DIF, key populations participants (sample 2) had 1.12 SD higher latent factor levels than other populations (see Table $5, p \leq 0.001$ ). DIF analyses also indicated that items 2,4 and 8 were statistically significant $(p \leq 0.001)$. As shown in Table 5 , after correcting for DIF, key populations had 1.14 SD higher latent factor levels compared to other populations (i.e., the effect of DIF on overall scores was of 0.02 standard deviations). The final model accounting for DIF had a good fit [chi-square $(23)=729.9, \mathrm{p} \leq 0.001, \mathrm{CFI}=0.97$, $\mathrm{TLI}=0.95$, RMSEA $=0.09$ (90\% CI: 0.08-0.09)].

Internal consistency reliability for each group were: key populations sample 1 ( $\alpha=0.76$; 95\% CI $0.71-0.80)$, key populations sample $2(\alpha=0.75 ; 95 \%$ CI $0.74-0.76)$, and other populations ( $\alpha=0.78$; 95\% CI $0.73-0.83$ ).

Construct validity results are shown in Table 6. We observed that participants who ever tested for HIV scored higher among key populations from sample 2 and other populations $(p<0.001$, both samples). Perceived Risk of HIV Scale scores for key populations of sample 2 were significantly higher among those engaging in highrisk sexual behavior irrespective of how high-risk behavior was measure $(p<0.001)$. Younger individuals scored lower than older individuals among key populations (sample 1: $p=0.09$; sample 2: $p=0.005$ ).

\section{Discussion}

In this study, we successfully performed a cross-cultural adaptation of the Brazilian Portuguese version of the Perceived Risk of HIV Scale. CFA showed that the single-factor structure of the scale had sufficiently good fit among all groups considered. Significant DIF was found for 3 items, and key populations had substantially higher latent factor levels compared to other populations. Our results indicate that this scale can be used among key populations in Brazil, such as GBM and transgender/non-binary individuals as well as other populations. 
Table 5 Factor loadings for the Perceived Risk of HIV Scale in key populations (sample 2) and other populations and influence of group on the overall estimates of latent factor score

\begin{tabular}{|c|c|c|c|c|}
\hline \multirow[t]{2}{*}{ Items } & \multicolumn{2}{|l|}{ Base model ${ }^{\mathrm{a}}$} & \multicolumn{2}{|c|}{ DIF corrected model ${ }^{b}$} \\
\hline & Factor loading & $95 \% \mathrm{Cl}$ & Factor loading & $95 \% \mathrm{Cl}$ \\
\hline $\begin{array}{l}\text { i01. What is your gut feeling about how likely you are to get } \\
\text { infected with HIV? }\end{array}$ & 0.773 & $0.76,0.79$ & 0.773 & $0.76,0.79$ \\
\hline i02. I worry about getting infected with HIV & 0.054 & $0.01,0.10$ & 0.023 & $-0.02,0.07$ \\
\hline i03. Picturing self getting HIV is something I find & 0.649 & $0.63,0.67$ & 0.649 & $0.63,0.67$ \\
\hline i04. I am sure I will NOT get infected with HIV & 0.636 & $0.62,0.65$ & 0.644 & $0.62,0.66$ \\
\hline i05. I feel vulnerable to HIV infection & 0.639 & $0.62,0.66$ & 0.639 & $0.62,0.66$ \\
\hline i06. There is a chance, no matter how small, I could get HIV & 0.545 & $0.52,0.57$ & 0.545 & $0.52,0.57$ \\
\hline i07. I think my chances of getting infected with HIV are: & 0.871 & $0.86,0.88$ & 0.871 & $0.86,0.88$ \\
\hline i08. Getting HIV is something I have & 0.392 & $0.35,0.42$ & 0.383 & $0.35,0.41$ \\
\hline \multicolumn{5}{|l|}{ Structural effect } \\
\hline Group on latent factor ${ }^{c}$ & 1.119 & $0.91,1.33$ & 1.143 & $0.93,1.36$ \\
\hline \multicolumn{5}{|l|}{ Direct effect on item attributable to group ${ }^{c}$} \\
\hline i02 & & & 1.675 & $1.50,1.86$ \\
\hline i04 & & & -0.552 & $-0.73,-0.38$ \\
\hline i08 & & & 0.550 & $0.38,0.72$ \\
\hline
\end{tabular}

Bold indicate $p$ value $\leq 0.001$

DIF differential item functioning

a Not corrected for DIF

${ }^{\text {b }}$ Correct for DIF for items 2, 4 and 8

3 Other populations used as reference

Table 6 Perceived Risk of HIV Scale scores according to age, HIV testing and HIV risk behavior. Brazil, 2020

\begin{tabular}{|c|c|c|c|c|c|c|c|c|c|}
\hline & \multicolumn{3}{|c|}{ Other populations } & \multicolumn{3}{|c|}{ Key populations, sample 1} & \multicolumn{3}{|c|}{ Key populations, sample 2} \\
\hline & $N=155$ & Score mean (SD) & $p$ value & $N=235$ & Score mean (SD) & $p$ value & $N=4107$ & $\begin{array}{l}\text { Score mean } \\
\text { (SD) }\end{array}$ & $p$ value \\
\hline Age (years) & & & 0.39 & & & 0.09 & & & 0.005 \\
\hline $18-24$ & 16 & $21.6(6.2)$ & & 37 & $24.4(5.3)$ & & 681 & $25.2(5.0)$ & \\
\hline$\geq 25$ & 139 & $20.4(5.4)$ & & 198 & $26.0(5.1)$ & & 3426 & $25.8(4.9)$ & \\
\hline HIV testing & & & $<.001$ & & & 0.26 & & & $<.001$ \\
\hline Never & 44 & $17.9(5.0)$ & & 30 & $24.8(5.9)$ & & 506 & $24.8(5.0)$ & \\
\hline At least once lifetime & 111 & $21.5(5.3)$ & & 205 & $25.9(5.1)$ & & 3601 & $25.8(4.9)$ & \\
\hline Condomless receptive anal sex & & & & & & & & & $<.001$ \\
\hline No & * & * & * & * & * & * & 2580 & $25.0(4.9)$ & \\
\hline Yes & * & * & * & * & * & * & 1527 & $27.0(4.7)$ & \\
\hline Number of male partners & & & & & & & & & $<.001$ \\
\hline$\leq 5$ & * & * & * & * & * & * & 2457 & $24.8(4.8)$ & \\
\hline$>5$ & * & * & * & * & * & * & 1650 & $27.0(4.7)$ & \\
\hline HIRI-MSM scale & & & & & & & & & $<.001$ \\
\hline Low & $*$ & * & * & * & * & * & 1831 & $24.4(4.8)$ & \\
\hline High & * & * & * & * & * & * & 2276 & $26.7(4.8)$ & \\
\hline
\end{tabular}

*Data not available

An important finding was that, for the two comparisons between key populations and other populations, three items of the Perceived Risk of HIV Scale (item 2:
"I worry about getting infected with HIV", item 4: "I am sure I will not get infected with HIV", and item 8: "Getting HIV is something I have") exhibited statistically 
significant DIF. However, the effect on overall scores of the Perceived Risk of HIV scale was negligible (0.10 SD and $0.02 \mathrm{SD}$ for the models considering other populations and key populations sample 1 and 2, respectively). Key populations had higher Perceived Risk of HIV scale scores on items 2 and 8 and lower scores on item 4 . These results suggest that scores from key populations and other populations can be validly compared and assumed to be measuring risk perception using the same metric. DIF would also negligibly influence overall scores.

The HIV epidemic in Brazil is highly concentrated on key populations including GBM and TGW, with HIV prevalence being 10-30 times higher among these populations $[2,4,5]$. Since the onset of the epidemic, HIV has been portrayed as a disease of gay men. Studies suggests that cultural constructions of sexuality influence an individual's perception of HIV risk and vulnerability [36]. In an analysis of individual- and partner-level factors associated with partner-specific perceptions of risk among GBM and TGW who had recently acquired HIV infection, both gay or transgender partners were more likely to be considered a source of infection than heterosexual partners [37]. These findings suggest a latent cultural logic that identifies GBM or TGW as "carriers of HIV disease" [36] independent of their actual objective risk of acquiring or transmitting HIV. We hypothesize that this association of HIV infection with GBM coupled with Brazil's heterosexist and transphobic society might explain key populations' much higher endorsement of item 2, "I worry about getting infected with HIV". Item 2 was endorsed by more than half of the participants from key populations (50.6\% sample 1 and $56.5 \%$ sample 2 responding that they "worry about getting HIV all of the time") whereas more than half of participants from other populations reported "worrying about getting HIV none of the time (24.5\%) and rarely (29.0\%)". This line of reasoning could also explain why the factor loading for item 2 was small among key populations (sample 1: 0.20 and sample 2: 0.03 compared to 0.54 for other populations, Table 3). A similar pattern may be observed for item 8 ("Getting HIV is something I have") which more than $80 \%$ of the participants from key populations (85.1\% of sample 1 and $82.5 \%$ of sample 2) responding that getting HIV is something they have "thought about often or sometimes" whereas almost half of participants from other populations answered "rarely" $(24.6 \%)$ and "never" (23.9\%) explaining the relatively low factor loadings for key populations (sample 1 and sample 2: 0.38 compared to 0.66 for other populations). Indeed, items 2 and 8 were found to be correlated in the CFA analysis. Taken together, these findings suggest that HIV is something key populations constantly think and worry about independently of their objective assessments of risk or of how salient HIV is to them. Furthermore, these results highlight the importance of measuring the different dimensions of risk perception as highlighted not only in regards to HIV [18] but also more broadly [38]. Finally, though the low factor loadings for items 2 and 8 could suggest that they be removed from the scale when assessing perceived HIV risk among key populations (thus consequently creating a different measure for key populations), we argue for its maintenance because it appropriately loaded in other populations, and to keep with a single uniform instrument that may be applied to all populations.

Confirming our hypotheses, among key populations from sample 2, for whom we had information on sexual behavior, participants who reported high risk sexual behavior (condomless receptive anal sex, $>5$ sexual partners and $\geq 10$ points in the HIRI-MSM risk score) scored higher on the Perceived Risk of HIV Scale than those who reported low risk behavior. These results suggest that perceived HIV risk, as measured by the proposed translated version of the scale, correlates with sexual behavior as supposed in theoretical models [14].

We found that participants who ever tested for HIV scored higher on the Perceived Risk of HIV scale than those who never tested for key populations and other populations. This positive correlation between scores in the Perceived Risk of HIV scale and ever testing for HIV was also found during the validation of the present scale to European Portuguese, which was conducted in the general population and with HIV-uninfected partners from serodifferent couples [39], and this association is corroborated by prior systematic review findings [40]. We also found that among key populations, younger participants scored lower on the Perceived Risk of HIV scale. Younger GBM aged 18-24 years reported lower perceived HIV risk in comparison to older GBM in a prior analysis in Brazil $[8,41]$. The possible misperception of HIV risk among the youngest could help explain the recent rise in HIV incidence among GBM aged 16-24 years in Brazil [2]. Another explanation for this finding is that younger individuals may be more optimistic of HIV treatment and prevention strategies and less fearful of HIV infection than older peers [42-44]. Although these results are of importance for the concurrent validity of Brazilian Portuguese version of The Perceived Risk of HIV Scale, these associations should be confirmed by larger studies in particular when thinking of the application of the scale in other populations for which our sample was small.

There are several study limitations to highlight. There was a difference in sample size between the groups. However, this difference may not have influenced the results as the initial confirmatory factor analysis yielded the similar model structures. Due to the cross-sectional design of 
the study, test-retest reliability and sensitivity to change of the translated HIV Perceived Risk scale could not be assessed. All collected data were self-reported by participants and may be subject to bias (social desirability bias). Also, participants were recruited from a convenience online sample and may not reflect the entire Brazilian population, although cellphones and internet connection are widely available in all socioeconomic strata of the Brazilian population $[45,46]$. Finally, a limitation of the MIMIC model we used is that it assessed uniform but not non-uniform DIF.

\section{Conclusions}

The HIV Perceived Risk Scale was effectively cross-culturally adapted to Brazilian Portuguese and validated. This instrument has shown to be practical, easy to administer, and could be useful in future studies to better measure perceived HIV risk and its association with engagement in high-risk sexual behaviors among a plurality of populations from Brazil.

\begin{abstract}
Abbreviations
AIDS: Acquired immunodeficiency syndrome; CFA: Confirmatory factor analysis; CFI: Comparative Fit Index; Cl: Confidence interval; DIF: Differential item functioning; GBM: Gay, bisexual and other men who have sex with men; HIRIMSM: HIV Incidence Risk Index for men who have sex with men; HIV: Human immunodeficiency virus; IQR: Interquartile range; MIMIC: Multiple indicator multiple cause; PrEP: Pre-exposure prophylaxis; RMSEA: Root Mean Square Error of Approximation; TLI:Tucker-Lewis Index; TGW: Transgender women who have sex with men.
\end{abstract}

\section{Supplementary Information}

The online version contains supplementary material available at https://doi. org/10.1186/s12955-021-01760-6.

Additional file 1. Escala de Percepção de Risco do HIV em Português do Brasil.

\section{Acknowledgements}

We would like to thank Roberto Gonçalves Ramalho for the valuable contribution and guidance during Translation Step.

\section{Authors' contributions}

Conceived study and designed surveys: TST, PML, LMSM, DRBB, VGV, BG. Study implementation, advertisement and procedures: TST, LMSM, DRBB. Data analysis: TST, PML, DH, BDT. Data analysis guidance and interpretation of findings: PML, CCAB, DH, BDT. Wrote paper: PML, TST, LMSM, DRBB, VGV, BG. Reviewed and critically revised the manuscript: CCAB, DH, BDT. All authors read and approved the final manuscript.

\section{Funding}

Dr. Luz was supported by Programa Inova FIOCRUZ, Edital Geração do Conhecimento/VPPCB, and Programa PrInt, Coordenação de Aperfeiçoamento de Pessoal de Nível Superior (CAPES)/FIOCRUZ. Dr. Torres was supported by Conselho Nacional de Desenvolvimento Científico e Tecnológico (CNPq, \#28/2018). Dr. Thombs was supported by a Fonds de recherche du QuébecSanté Distinguished Scholar Award.

\section{Availability of data and materials}

The datasets analyzed during the current study are available from the corresponding author on reasonable request.

\section{Ethics approval and consent to participate}

This analysis is part of a larger project to study GBM's behavior, risk perception and knowledge of HIV transmission, prevention and treatment in Brazil, which was approved by INI Evandro Chagas-FIOCRUZ institutional review board (\#CAAE 01777918.0.0000.5262) in accordance with all applicable regulations. All study participants provided electronic informed consent before initiating the survey. Informed consent contained information on the length of time of the survey, data stored and investigator name and contact. No incentives were provided.

\section{Consent for publication}

All authors fulfill the criteria for authorship, and have read and approved the final version of this manuscript.

\section{Competing interests}

The authors declare that they have no competing interests.

\section{Author details}

${ }^{1}$ Instituto Nacional de Infectologia Evandro Chagas, Fundação Oswaldo Cruz, Av. Brasil 4365, Manguinhos, Rio de Janeiro 21040-900, Brazil. ${ }^{2}$ Research Institute of the McGill University Health Centre, Montreal, Canada. ${ }^{3}$ Department of Applied Statistics, Social Science, and Humanities, New York University, New York, NY, USA. ${ }^{4}$ Center for Practice and Research and the Intersection of Information, Society, and Methodology, New York University, New York, NY, USA.

${ }^{5}$ Lady Davis Institute for Medical Research, Jewish General Hospital, Montréal, Québec, Canada. ${ }^{6}$ Departments of Psychiatry; Epidemiology, Biostatistics and Occupational Health; Medicine; Psychology; Educational and Counselling Psychology, and Biomedical Ethics Unit, McGill University, Montréal, Québec, Canada.

Received: 15 November 2020 Accepted: 31 March 2021

Published online: 09 April 2021

\section{References}

1. UNAIDS. AIDSinfo [Internet]. [cited 2020 May 26]. https://aidsinfo.unaids. org/.

2. Brasil, Ministério da Saúde. Boletim Epidemiológico de HIV/Aids 2019 [Internet]. 2020 [cited 2020 May 27]. http://www.aids.gov.br/pt-br/pub/ 2019/boletim-epidemiologico-de-hivaids-2019.

3. Luz PM, Veloso VG, Grinsztejn B. The HIV epidemic in Latin America: accomplishments and challenges on treatment and prevention. Curr Opin HIV AIDS. 2019;14:366.

4. Kerr L, Kendall C, Guimarães MDC, Mota RS, Veras MA, Dourado I, et al. HIV prevalence among men who have sex with men in Brazil: results of the 2 nd national survey using respondent-driven sampling. Medicine. 2018;97(1S):S9-15.

5. Grinsztejn B, Jalil EM, Monteiro L, Velasque L, Moreira RI, Garcia ACF, et al. Unveiling of HIV dynamics among transgender women: a respondent-driven sampling study in Rio de Janeiro, Brazil. Lancet HIV. 2017;4(4):e169-76.

6. Torres TS, De Boni RB, de Vasconcellos MT, Luz PM, Hoagland B, Moreira $\mathrm{Rl}$, et al. Awareness of prevention strategies and willingness to use preexposure prophylaxis in Brazilian men who have sex with men using apps for sexual encounters: online cross-sectional study. JMIR Public Health Surveill. 2018;4(1):e11.

7. Torres TS, Konda KA, Vega-Ramirez EH, Elorreaga OA, Diaz-Sosa D, Hoagland B, et al. Factors associated with willingness to use pre-exposure prophylaxis in Brazil, Mexico, and Peru: web-based survey among men who have sex with men. JMIR Public Health Surveill. 2019;5(2):e13771.

8. Torres TS, Luz PM, De Boni RB, de Vasconcellos MTL, Hoagland B, Garner $A$, et al. Factors associated with PrEP awareness according to age and willingness to use HIV prevention technologies: the 2017 online survey among MSM in Brazil. AIDS Care. 2019;31(10):1193-202. 
9. Guimarães MDC, Kendall C, Magno L, Rocha GM, Knauth DR, Leal AF, et al. Comparing HIV risk-related behaviors between 2 RDS national samples of MSM in Brazil, 2009 and 2016. Medicine. 2018;97:S62-8.

10. Torres TS, Bastos LS, Kamel L, Bezerra DRB, Fernandes NM, Moreira RI, et al. Do men who have sex with men who report alcohol and illicit drug use before/during sex (chemsex) present moderate/high risk for substance use disorders? Drug Alcohol Depend. 2020;209:107908.

11. World Health Organization (WHO). WHO | Brazil begins PrEP roll-out on World AIDS Day [lnternet]. WHO. [cited 2019 Jul 9]. http://www.who.int/ hiv/mediacentre/news/brazil-prep/en/.

12. Torres TS, Marins LMS, Veloso VG, Grinsztejn B, Luz PM. How heterogeneous are MSM from Brazilian cities? An analysis of sexual behavior and perceived risk and a description of trends in awareness and willingness to use pre-exposure prophylaxis. BMC Infect Dis. 2019;19(1):1067.

13. Rosenstock IM. Historical origins of the health belief model. Health Educ Monogr. 1974;2(4):328-35.

14. Catania JA, Kegeles SM, Coates TJ. Towards an understanding of risk behavior: an aids risk reduction model (ARRM). Health Educ $\mathrm{Q}$ 1990;17(1):53-72.

15. For the PrEP Brasil Study Team, Hoagland B, De Boni RB, Moreira RI, Madruga JV, Kallas EG, et al. Awareness and willingness to use preexposure prophylaxis (PrEP) among men who have sex with men and transgender women in Brazil. AIDS Behav. 2017;21(5):1278-87.

16. Jalil EM, Grinsztejn B, Velasque L, Ramos Makkeda A, Luz PM, Moreira RI, et al. Awareness, willingness, and PrEP eligibility among transgender women in Rio de Janeiro, Brazil. JAIDS J Acquir Immune Defic Syndr. 2018;79(4):445-52.

17. Ferreira MP. Nível de conhecimento e percepção de risco da população brasileira sobre o HIV/Aids, 1998 e 2005. Rev Saúde Pública. 2008;42(suppl 1):65-71.

18. Napper LE, Fisher DG, Reynolds GL. Development of the perceived risk of HIV scale. AIDS Behav. 2012;16(4):1075-83.

19. Martins A, Chaves C, Canavarro MC, Pereira M. Psychometric properties of the European Portuguese version of the perceived risk of HIV scale in the general population and HIV-uninfected partners from sero-different couples. BMC Public Health. 2019;19(1):1336.

20. Beaton DE, Bombardier C, Guillemin F, Ferraz MB. Guidelines for the process of cross-cultural adaptation of self-report measures. Spine. 2000;25(24):3186-91.

21. Meade AW, Craig SB. Identifying careless responses in survey data. Psychol Methods. 2012;17(3):437.

22. Grant RM, Lama JR, Anderson PL, McMahan V, Liu AY, Vargas L, et al. Preexposure chemoprophylaxis for HIV prevention in men who have sex with men. N Engl J Med. 2010;363(27):2587-99.

23. Grinsztejn B, Hoagland B, Moreira RI, Kallas EG, Madruga JV, Goulart $S$, et al. Retention, engagement, and adherence to pre-exposure prophylaxis for men who have sex with men and transgender women in PrEP Brasil: 48 week results of a demonstration study. Lancet HIV. 2018;5(3):e136-45.

24. Smith DK, Pals SL, Herbst JH, Shinde S, Carey JW. Development of a clinical screening index predictive of incident HIV infection among men who have sex with men in the United States. JAIDS J Acquir Immune Defic Syndr. 2012;60(4):421-7.

25. US Centers for Disease Control (CDC). Preexposure prophylaxis for the prevention of HIV infection in the United States-2017 update clinical providers' supplemenT [Internet]. 2017. https://www.cdc.gov/hiv/pdf/ risk/prep/cdc-hiv-prep-provider-supplement-2017.pdf.

26. Kwakkenbos L, Arthurs E, van den Hoogen FHJ, Hudson M, van Lankveld WGJM, Baron M, et al. Cross-language measurement equivalence of the center for epidemiologic studies depression (CES-D) scale in systemic sclerosis: a comparison of Canadian and Dutch patients. PLoS ONE. 2013;8(1):e53923.

27. Muthen $L K$, Muthen BO. Mplus statistical analysis with latent variables. User's Guide. [Internet]. 2020. https://www.statmodel.com/download/ usersguide/MplusUserGuideVer_8.pdf.
28. Tucker $L R$, Lewis C. A reliability coefficient for maximum likelihood factor analysis. Psychometrika. 1973;38(1):1-10.

29. Bentler PM. Comparative fit indexes in structural models. Psychol Bull. 1990;107(2):238-46.

30. Steiger JH. Structural model evaluation and modification: an interval estimation approach. Multivariate Behav Res. 1990;25(2):173-80.

31. Reise SP, Widaman KF, Pugh RH. Confirmatory factor analysis and item response theory: two approaches for exploring measurement invariance. Psychol Bull. 1993:114(3):552-66.

32. Hu L, Bentler PM. Cutoff criteria for fit indexes in covariance structure analysis: conventional criteria versus new alternatives. Struct Equ Model. 1999;6(1):1-55.

33. McDonald RP, Ho M-HR. Principles and practice in reporting structural equation analyses. Psychol Methods. 2002;7(1):64-82.

34. Taber KS. The use of Cronbach's alpha when developing and reporting research instruments in science education. Res Sci Educ. 2018:48(6):1273-96.

35. The R Project for Statistical Computing. [cited 2020 May 26]. https:// www.r-project.org/.

36. Clark J, Salvatierra J, Segura E, Salazar X, Konda K, Perez-Brumer A, et al. Moderno love: sexual role-based identities and HIV/STI prevention among men who have sex with men in Lima. Peru AIDS Behav. 2013;17(4):1313-28

37. Blair CS, Segura ER, Perez-Brumer AG, Sanchez J, Lama JR, Clark JL. Sexual orientation, gender identity and perceived source of infection among men who have sex with men (MSM) and transgender women (TW) recently diagnosed with HIV and/or STI in Lima. Peru AIDS Behav. 2016;20(10):2178-85.

38. Ferrer RA, Klein WMP, Persoskie A, Avishai-Yitshak A, Sheeran P. The tripartite model of risk perception (TRIRISK): distinguishing deliberative, affective, and experiential components of perceived risk. Ann Behav Med. 2016;50(5):653-63.

39. Chard AN, Finneran C, Sullivan PS, Stephenson R. Experiences of homophobia among gay and bisexual men: results from a cross-sectional study in seven countries. Cult Health Sex. 2015;17(10):1174-89.

40. Evangeli M, Pady K, Wroe AL. Which psychological factors are related to HIV testing? A quantitative systematic review of global studies. AIDS Behav. 2016;20(4):880-918.

41. Torres TS, Konda KA, Vega-Ramirez EH, Elorreaga-Reyes OA, Diaz-Sosa D, Hoagland B, et al. Characteristics of younger MSM and association of age with PrEP awareness and willingness in Brazil, Mexico and Peru [Abstract TUPEC490]. In Mexico City, Mexico; 2019.

42. Lapinski MK, Rimal RN, Klein KA, Shulman HC. Risk perceptions of people living with HIV/AIDS: how similarity affects optimistic bias. J Health Psychol. 2009;14(2):251-7.

43. Huebner DM, Rebchook GM, Kegeles SM. A longitudinal study of the association between treatment optimism and sexual risk behavior in young adult gay and bisexual men. JAIDS J Acquir Immune Defic Syndr. 2004:37(4):1514-9.

44. Stockman J, Schwarcz S, Butler L, de Jong B, Chen S, Delgado V, et al. HIV prevention fatique among high-risk populations in San Francisco. JAIDS J Acquir Immune Defic Syndr. 2004;35(4):432-4.

45. Comitê Gestor da Internet no Brasil (CGIBR). C2A—Usuários de internetindicador ampliado 2019 [Internet]. 2019 [cited 2020 Jun 4]. https://cetic. $\mathrm{br} / \mathrm{pt} / \mathrm{tics} / \mathrm{domicilios} / 2019 /$ individuos/C2A/

46. Comitê Gestor da Internet no Brasil (CGIBR). J2 —indivíduos que possuem telefone celular 2019 [Internet]; 2020. https://cetic.br/pt/tics/domicilios/ 2019/individuos/J2/.

\section{Publisher's Note}

Springer Nature remains neutral with regard to jurisdictional claims in published maps and institutional affiliations. 